\title{
PENGARUH KOMITMEN PROFESIONAL TERHADAP KEPUASAN KERJA AUDITOR PADA BADAN PEMERIKSA KEUANGAN RI PERWAKILAN PROVINSI SULAWESI TENGGARA
}

\author{
Oleh \\ Arifuddin ${ }^{1}$, Sulvariany Tamburaka ${ }^{2}$, Nurlina Sari $^{3}$ \\ Jurusan Akuntansi Fakultas Ekonomi dan Bisnis Universitas Halu Oleo Kendari \\ Sulawesi Tenggara
}

\begin{abstract}
ABSTRAK
Tujuan dari penelitian ini adalah untuk mengetahui pengaruh komitmen profesional terhadap kepuasan kerja auditor di BPK (Badan Pemeriksa Keuangan) RI Perwakilan Sulawesi Tenggara. Jenis penelitian yang digunakan dalam penelitian ini adalah penelitian kualitatif dan kuantitatif. Teknik sampel yang digunakan dalam penelitian ini adalah sampling jenuh, dimana sampel dalam penelitian ini merupakan auditor pada BPK (Badan Pemeriksa Keuangan) RI Perwakilan Sulawesi Tenggara sebanyak 27 orang. Instrumen penelitian menggunakan kuesioner, sedangkan alat analisis yang digunakan adalah analisis regresi linear sederhana. Hasil penelitian ini menunjukkan Koefisien regresi bernilai positif, sehingga dapat dikatakan bahwa komitmen profesional (variabel $\mathrm{X}$ ) terhadap kepuasan kerja auditor (variabel Y) berpengaruh signifikan.
\end{abstract}

Kata Kunci : Komitmen, Kepuasan Kerja.

\section{ABSTRACT}

This study was to determine the effect of professional commitment on job satisfaction of auditors at the BPK (BPK) RI Representative of Southeast Sulawesi. This type of research used in this research is qualitative and quantitative research. The sample technique used in this study was saturated sampling, where the sample in this study was an auditor at the BPK (BPK) RI Representative of Southeast Sulawesi as many as 27 people. The research instrument used a questionnaire, while the analysis tool used was simple linear regression analysis. The results of this study indicate that the regression coefficient is positive, so it can be said that professional commitment (variable X) to auditor job satisfaction (variable Y) has a significant effect.

Keywords: Commitment, Job Satisfaction.

\section{PENDAHULUAN}

Keberhasilan dan kinerja seseorang dalam suatu bidang pekerjaan banyak ditentukan oleh tingkat kompetensi, profesionalisme, dan juga komitmennya terhadap bidang yang ditekuninya (Sri Trisnaningsuh, 2001). Sebagai suatu yang berhubungan positif dengan kinerja, komitmen merupakan suatu sikap dan perilaku yang dapat dipandang sebagai penggerak dari motivasi seseorang dalam bekerja adalah saling terkait erat. Suatu komitmen organisasional menunjukkan suatu daya dari seseorang dalam mengidentifikasikan keterlibatannya dalam suatu bagian organisasi. Komitmen organisasional akan menimbulkan rasa ikut memiliki (sense of belonging) terhadap organisasi (Mowday, Porter, dan Steers 1982).

Kepuasan kerja merupakan suatu perasaan yang menunjukkan apakah seorang karyawan menyukai pekerjaan mereka. Kepuasan kerja memiliki keterkaitan dengan dengan kepuasan hidup. Pekerjaan merupakan hal yang sangat penting dalam kehidupan, sehingga kepuasan kerja dapat memengaruhi kepuasan hidup seseorang. Wexley dan Yuki 
(1988:154) mengungkapkan kepuasan kerja menjadi penting dalam dunia kerja karena diyakini bahwa kepuasan kerja yang tinggi akan mendorong peningkatan kinerja, baik individu maupun kelompok, yang pada gilirannya akan meningkatkan efektivitas perusahaan secara keseluruhan.

Penelitian mengenai komitmen terhadap kepuasan kerja auditor merupakan topik yang menarik untuk di teliti lebih lanjut. A.A. Gde Dwi Aditya dan Made Gede Wirakusuma (2013) menyebutkan bahwa komitmen profesional tidak berpengaruh terhadap kepuasan kerja auditor, dengan kata lain pengaruh komitmen profesional tidak signifikan, begitu juga dalam penelitian Bhrasatya (2010) yang berjudul pengaruh komitmen organisasional dan komitmen profesional terhadap kepuasan kerja auditor menyatakan bahwa variabel komitmen profesional tidak berpengaruh terhadap kepuasan kerja auditor. Sedangkan penelitian Zulfikar (2013) membuktikkan bahwa komitmen profesional berpengaruh positif signifikan terhadap kepuasan kerja auditor. Karena adanya perbedaan tersebut, maka penulis ingin membahas variabel pada penelitian sebelumnya dengan mengambil objek penelitian berbeda yakni di BPK Perwakilan Provinsi Sulawesi Tenggara. Dengan judul penelitian "Pengaruh Komitmen Profesional Terhadap Kepuasan Kerja Auditor (Studi Pada Badan Pemeriksa KeuanganRI Perwakilan Provinsi Sulawesi Tenggara)".

\section{Komitmen Profesional}

\section{TINJAUAN PUSTAKA}

Komitmen merupakan salah satu unsur penting dalam dunia kerja saat ini karena komitmen bisa mempengaruhi keberhasilan kerja dan kinerja seseorang dalam pekerjaannya. Komitmen adalah perjanjian untuk melakukan sesuatu (KBBI). Menurut panggabean (2008) komitmen merupakan langkah atau tindakan yang diambil untuk menopang suatu pilihan tindakan tertentu sehingga pilihan tindakan itu dapat dijalankan dengan mantap dan sepenuh hati.

\section{Keterkaitan Antara Variabel Penelitian Hipotesis}

Komitmen profesional dapat didefinisikan sebagai: (1) sebuah kepercayaan pada dan penerimaan terhadap tujuan-tujuan dan nilai-nilai dari profesi, (2) sebuah kemauan untuk menggunakan usaha yang sungguh-sungguh guna kepentingan profesi, (3) sebuah keinginan untuk memelihara keanggotaan dalam profesi (Trianingsih, 2003:202). Profesi yang memiliki tingkat kepercayaan dan penerimaan yang terhadap tujuan profesi dan berkeinginan kuat untuk tetap menjadi bagian dari profesi. Sedangkan kepuasan kerja adalah suatu sikap umum individu terhadap pekerjaannya sebagai perbedaan antara banyaknya ganjaran yang diterima pekerja dan banyaknya yang diyakini yang seharusnya diterima (Robbins, 2003:101). Dengan adanya komitmen profesional makan akan mempengaruhi tingkat produktivitas seseorang dalam bekerja dan menimbulkan kepuasan kerja. Dalam penelitian yang dilakukan Ferby Mutia Edwy (2016) menyatakan bahwa komitmen profesional berpengaruh signifikan terhadap kepuasan kerja.

Studi lain yang dilakukan oleh Achmad Badjuri Jaeni (2013) tentang "Pengaruh Komitmen Terhadap Kepuasan Kerja Auditor Dengan Motivasi Sebagai Variabel Intervening (Studi Empirik Pada Kantor Akuntan Publik Di Jawa Tengah" yakni menghasilkan beberapa hipotesis tentang pengaruh komitmen profesional terhadap motivasi kerja auditor, dimana hipotesis secara keseluruhan menyebutkan bahwa memiliki pengaruh positif yang signifikan terhadap kepuasan kerja. 
a. Paradigma Penelitian

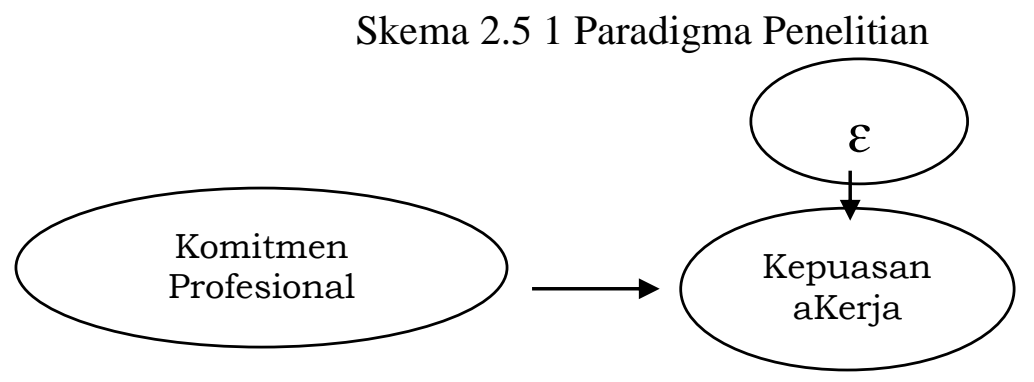

b. Perumusan Hipotesis

Penelitian Zulfikar (2013) "Pengaruh komitmen profesionalisme, komitmen organisasi, motivasi kerja, dan lotus of control terhadap kepuasan kerja auditor" (Studi Empiris pada Kantor BPKRI Perwakilan Provinsi Riau. Hasil Penelitian ini Secara parsial komitmen profesional berpengaruh secara signifikan terhadap kepuasan kerja auditor sebesar 47,9\%.

H1: Terdapat pengaruh yang signifikan antara komitmen Profesional terhadap Kepuasan Kerja Auditor BPKRI Provinsi Sulawesi Tenggara.

\section{METODE PENELITIAN}

Objek penelitian ini adalah pengaruh komitmen profesional terhadap kepuasan kerja auditor. Penelitian ini dilakukan di kantor Badan Pemeriksa Keuangan Perwakilan Provinsi Sulawesi Tenggara yang beralamat di jalan sao-sao no. 10, KelurahanBende, KecamatanKadia, Kota Kendari, Sulawesi Tenggara, kode pos 93100.

Populasi dalam penelitian ini adalah seluruh auditor yang terdaftar dan bekerja pada Badan Pemeriksa Keuangan Perwakilan Provinsi Sulawesi Tenggara yang berjumlah 27 orang. Sedangkan teknik sampel yang digunakan dalam penelitian ini adalah sampling jenuh yaitu teknik penentuan sampel bila semua anggota populasi digunakan sebagai sampel. Adapun jumlah sampel sama dengan jumlah populasi yang merupakan auditor BPK (Badan Pemeriksa Keuangan) RI Perwakilan Sulawesi Tenggara sebanyak 27 orang. Jenis data yang digunakan dalam penelitian ini adalah data kualitatif dalam berupa uraian penjelasan dari variabel dan objek penelitian dan juga pertanyaan dalam kuesioner yang akan diklasifikasikan kedalam kategori menggunakan skala likert. Adapun data kuantitatif dalam penelitian ini adalah jawaban responden atas pertanyaan kuesioner yang diukur menggunakan skor dari skala likert.

Data penelitian ini berasal dari dua sumber yaitu,data primer yang diperoleh dari jawaban yang akan diberikan oleh responden dalam suatu instrument penelitian yang berupa daftar pernyataan atau kuesioner pada objek yang diteliti. Data sekunder, yaitu data yang biasanya telah dikumpulkan oleh lembaga pengumpul data dan dipublikasikan kepada masyarakat pengguna data (Kuncoro, 2009:148). Data sekunder diperoleh dari Badan Pemeriksa Keuangan RI perwakilan Provinsi Sulawesi Tenggara, yang berupa profil.

Teknik pengolahan data merupakan suatu proses untuk mengartikan data-data sesuai dengan tujuan, rancangan dan sifat penelitian. Adapun metode pengolahan data yang digunakan dalam penelitian ini adalah :

1. Editing, yaitu memeriksa kelengkapan jawaban responden, meneliti kekonsistenan jawaban, dan menyeleksi keutuhan kuesioner sehingga data siap diproses.

2. Coding, yaitu mengkode atau memisahkan data berdasarkan klasifikasi variabel.

3. Tabulasi, yaitu memasukkan data yang sudah dikelompokkan ke dalam bentuk distribusi frekuensi. 


\section{HASIL DAN PEMBAHASAN}

\section{Tingkat Pengembalian Kuesioner}

Data penelitian ini dikumpulkan dengan menyebarkan 27 kuesioner kepada auditor pada Badan Pemeriksa Keuangan Perwakilan Provinsi Sulawesi Tenggara. Tingkat pengembalian kuesioner dapat dilihat pada tabel berikut :

Tabel 4.1

Tingkat Pengembalian Kuesioner

\begin{tabular}{|l|l|l|}
\hline Keterangan & Jumlah & Persentase \\
\hline Jumlah kuesioner yang disebar & $\mathbf{2 7}$ & $100 \%$ \\
\hline Jumlah kuesioner yang tidak kembali & - & - \\
\hline Jumlah kuesioner yang kembali & 27 & $100 \%$ \\
\hline Jumlah kuesioner yang tidak dapat diolah & - & - \\
\hline Jumlah kuesioner yang dapat diolah & $\mathbf{2 7}$ & $100 \%$ \\
\hline
\end{tabular}

\section{Sumber : Data Primer diolah tahun 2020}

\section{Karakteristik Responden}

Karakteristik responden dapat dilihat melalui deskripsi responden. Deskripsi responden terdiri dari jenis kelamin, usia, masa kerja, dan tingkat pendidikan. Hal tersebut dimaksudkan untuk menjelaskan latar belakang responden yang menjadi sampel dalam penelitian ini. Data penelitian dikumpulkan dengan menyebarkan 27 kuesioner secara langsung di Badan Pemeriksa Keuangan Perwakilan Provinsi Sulawesi Tenggara sesuai dengan ukuran sampel yang telah ditentukan dalam bab sebelumnya. Deskripsi Responden dapat dilihat pada tabel berikut:

Tabel 4. 2

\section{Responden Berdasarkan Jenis Kelamin}

\begin{tabular}{|l|l|l|l|}
\hline \multirow{2}{*}{ No. } & \multirow{2}{*}{ Jenis Kelamin } & Frekuensi \\
\cline { 3 - 4 } & & Orang & Persentase \\
\hline $\mathbf{1}$ & Laki-laki & $\mathbf{2 1}$ & $\mathbf{7 8 \%}$ \\
\hline $\mathbf{2}$ & Perempuan & $\mathbf{6}$ & $\mathbf{2 2 \%}$ \\
\hline Jumlah & $\mathbf{2 7}$ & $\mathbf{1 0 0 \%}$ \\
\hline
\end{tabular}

Sumber: Data Primer diolah tahun 2020

Tabel 4.2 diatas, terlihat bahwa responden yang paling banyak berpartisipasi pada penelitian ini berjenis kelamin laki-laki yaitu sebanyak 21 orang $(78 \%)$ dan yang berjenis kelamin perempuan sebanyak 6 orang $(22 \%)$.

Tabel 4. 3

Responden Berdasarkan Usia

\begin{tabular}{|l|l|l|l|}
\hline \multirow{2}{*}{ No. } & \multirow{2}{*}{ Usia } & Frekuensi & \\
\cline { 3 - 4 } & & Orang & Persentase \\
\hline $\mathbf{2}$ & 20-30 Tahun & 4 & $15 \%$ \\
\hline 3 & 31-40 Tahun & 18 & $67 \%$ \\
\hline Jumlah & $>41$ Tahun & 5 & $19 \%$ \\
\hline
\end{tabular}

Sumber: Data Primer diolah tahun 2020

Tabel 4.3 diketahui bahwa auditor Badan Pemeriksa Keuangan yang menjadi responden dalam penelitian ini berusia antara 20-30 tahun berjumlah 4 orang (15\%), responden berusia antara 31-40 tahun berjumlah 18 orang (67\%), dan responden yang berusia diatas 41 tahun berjumlah 5 orang (19\%). 
Tabel 4. 4

Responden Berdasarkan Masa Kerja

\begin{tabular}{|l|l|l|l|}
\hline \multirow{2}{*}{ No. } & \multirow{2}{*}{ Lama Bekerja } & Frekuensi \\
\cline { 3 - 4 } & & Orang & Persentase \\
\hline 1 & 1-10 Tahun & 21 & $\mathbf{7 8 \%}$ \\
\hline 2 & 11-20 Tahun & 5 & $19 \%$ \\
\hline 3 & $>20$ Tahun & 1 & $\mathbf{4 \%}$ \\
\hline Jumlah & & $27 \%$ & $100 \%$ \\
\hline
\end{tabular}

Sumber: Data Primer diolah tahun 2020

Tabel 4.4 diketahui bahwa masa kerja auditor Badan Pemeriksa Keuangan yang menjadi responden dalam penelitian ini antara 1-10 tahun berjumlah 21 orang (78\%), responden dengan masa kerja antara 11-20 tahun berjumlah 5 orang (19\%) dan responden dengan masa kerja diatas 20 tahun berjumlah 1 orang (4\%).

Tabel 4. 5

Responden Berdasarkan Tingkat Pendidikan

\begin{tabular}{|l|l|l|l|}
\hline \multirow{2}{*}{ No. } & \multirow{2}{*}{ Tingkat Pendidikan } & Frekuensi & \\
\cline { 3 - 4 } & & Orang & Persentase \\
\hline 1 & D3 & 1 & $4 \%$ \\
\hline 2 & S1 & 22 & $\mathbf{8 1 \%}$ \\
\hline 3 & S2 & 4 & $15 \%$ \\
\hline Jumlah & 27 & $100 \%$ \\
\hline
\end{tabular}

Sumber: Data Primer diolah tahun 2020

Tabel 4.5 diketahui bahwa mayoritas responden berpendidikan S1 berjumlah 22 orang, D3 berjumlah 1 orang, S2 berjumlah 4 orang.

\section{Deskripsi Variabel Penelitian}

a. Komitmen Profesional (X)

Ukuran penilaian variabel Sistem Teknologi Informasi didasarkan pada indikator pengumpulan, proses, distribusi, dan evaluasi. Keseluruhan indikator tersebut terdiri dari masing-masing 2 item pernyataan. Penilaian variabel independen yakni Sistem Teknologi Informasi dimaksudkan untuk melihat bentuk mekanisme pengelolaan sistem teknologi informasi menggunakan Sistem Aplikasi Satker (SAS). Adapun distribusi jawaban untuk variabel Sistem Teknologi Informasi yang disusun berdasarkan ringkasan jawaban kuesioner responen adalah sebagai berikut.

\section{Tabel 4.5}

Distribusi Kualifikasi Jawaban Untuk Variabel Sistem Komitmen Profesional

\begin{tabular}{|c|c|c|c|c|c|c|c|c|c|c|}
\hline \multirow{3}{*}{ Item } & \multicolumn{10}{|c|}{ Frekuensi Jawaban Responden } \\
\hline & \multicolumn{2}{|c|}{ STS(1) } & \multicolumn{2}{|c|}{$\mathbf{T S}(2)$} & \multicolumn{2}{|c|}{$\mathbf{N}(\mathbf{3})$} & \multicolumn{2}{|c|}{$\mathbf{S ( 4 )}$} & \multicolumn{2}{|c|}{$\mathbf{S S}(5)$} \\
\hline & $\mathbf{F}$ & $\%$ & $\mathbf{F}$ & $\%$ & $\mathbf{F}$ & $\%$ & $\mathbf{F}$ & $\%$ & $\mathbf{F}$ & $\%$ \\
\hline $\mathrm{X} 1.1$ & $\mathrm{O}$ & $\mathrm{O}$ & $\mathrm{O}$ & $\mathrm{O}$ & $\mathrm{O}$ & $\mathrm{O}$ & 21 & 77,78 & 6 & 22,22 \\
\hline $\mathrm{X} 1.2$ & $\mathrm{O}$ & $\mathrm{O}$ & $\mathrm{O}$ & $\mathrm{O}$ & $\mathrm{O}$ & $\mathrm{O}$ & 18 & 66,67 & 9 & 33,33 \\
\hline $\mathrm{X} 1.3$ & $\mathrm{O}$ & $\mathrm{O}$ & $\mathrm{O}$ & $\mathrm{O}$ & $\mathrm{O}$ & $\mathrm{O}$ & 21 & 77,78 & 6 & 22,22 \\
\hline$X 1.4$ & 0 & $\mathrm{O}$ & $\mathrm{O}$ & $\mathrm{O}$ & $\mathrm{O}$ & $\mathrm{O}$ & 17 & 62,96 & 10 & 37,04 \\
\hline$X 1.5$ & 0 & 0 & 0 & $\mathrm{O}$ & 0 & $\mathrm{O}$ & 18 & 66,67 & 9 & 33,33 \\
\hline$X 1.6$ & $\mathrm{O}$ & $\mathrm{O}$ & 0 & $\mathrm{O}$ & 2 & 7,41 & 17 & 62,96 & 8 & 29,63 \\
\hline $\mathrm{X} 1.7$ & 0 & 0 & 0 & $\mathrm{O}$ & 2 & 7,41 & 15 & 55,56 & 10 & 37,04 \\
\hline $\mathrm{X} 1.1$ & 0 & 0 & 0 & $\mathrm{O}$ & 0 & 0 & 21 & 77,78 & 6 & 22,22 \\
\hline $\mathrm{X} 1.2$ & $\mathrm{O}$ & $\mathrm{O}$ & $\mathrm{O}$ & $\mathrm{O}$ & 1 & 3,70 & 18 & 66,67 & 8 & 29,63 \\
\hline
\end{tabular}

Sumber : Data Diolah Tahun 2020 
Untuk item pertanyaan pada indikator loyalitas terhadap pemeriksa mayoritas jawaban responden secara berurut khusus pada item pertanyaan (X1.1) yaitu 77,78\% atau 21 orang menyatakan setuju, 22,22\% atau 6 orang menyatakan sangat setuju. Pada item pertanyaan (X1.2) yaitu 66,67\% atau 18 orang menyatakan setuju, 33,33\% atau 9 orang menyatakan sangat setuju. Pada item pertanyaan (X1.3) yaitu $77,78 \%$ atau 9 orang menyatakan setuju, 22,22\% atau 6 orang menyatakan sangat setuju. Pada item pertanyaan (X1.2) yaitu 66,67\% atau 18 orang menyatakan setuju, 33,33\% atau 9 orang menyatakan sangat setuju. Pada item pertanyaan (X1.3) yaitu 77,78\% atau 9 orang menyatakan setuju, $22,22 \%$ atau 6 orang menyatakan sangat setuju. Pada item pertanyaan (X1.4) yaitu 62,96\% atau 17 orang menyatakan setuju, 37,04\% atau 10 orang menyatakan sangat setuju. Pada item pertanyaan (X1.5) yaitu 66,67\% atau 18 orang menyatakan setuju, 33,33\% atau 9 orang menyatakan sangat setuju. Pada item pertanyaan (X1.6) yaitu 62,96\% atau 17 orang menyatakan setuju, 29,63\% atau 8 orang menyatakan sangat setuju, 7,41\% atau 2 orang menyatakan netral.Sedangkan pada item pertanyaan (X1.7) yaitu 55,56\% atau 15 orang menyatakan setuju, 37,04\% atau 10 orang menyatakan sangat setuju, 7,41\% atau 2 orang menyatakan netral.

Untuk item pertanyaan pada indikator kompetensi profesi pemeriksa mayoritas jawaban responden secara berurut khusus pada item pertanyaan (X2.1) yaitu 77,78\% atau 21 orang menyatakan setuju, $22,22 \%$ atau 6 orang menyatakan sangat setuju dan. Untuk item pertanyaan (X2.2) yaitu $66,67 \%$ atau 18 orang menyatakan setuju, 29,63\% atau 8 orang menyatakan sangat setuju dan $3,70 \%$ atau 1 orang menyatakan netral. Untuk item pertanyaan (X2.3) yaitu 74,07\% atau 20 orang menyatakan setuju, 25,93\% atau 7 orang menyatakan sangat setuju. Untuk item pertanyaan (X2.4) yaitu 66,67\% atau 18 orang menyatakan setuju, 29,63\% atau 8 orang menyatakan sangat setuju dan 3,70\% atau 1 orang menyatakan netral.

b. Kepuasan Kerja (Y)

Variabel kepuasan kerja auditor dibentuk indikator yaitu kepuasan kerja terhadap 6 pertanyaan. Adapun distribusi jawaban untuk variabel kepuasam kerja dan persentase kecenderungan skor jawaban adalah sebagai berikut :

\begin{tabular}{|c|c|c|c|c|c|c|c|c|c|c|}
\hline \multirow{3}{*}{ Item } & \multicolumn{10}{|c|}{ Frekuensi Jawaban Responden } \\
\hline & \multicolumn{2}{|c|}{ STS(1) } & \multicolumn{2}{|c|}{$\mathrm{TS}(2)$} & \multicolumn{2}{|c|}{$\mathbf{N}(3)$} & \multicolumn{2}{|c|}{$S(4)$} & \multicolumn{2}{|c|}{ SS(5) } \\
\hline & $\mathbf{F}$ & $\%$ & $\mathbf{F}$ & $\%$ & $\mathbf{F}$ & $\%$ & $\mathbf{F}$ & $\%$ & $\mathbf{F}$ & $\%$ \\
\hline Y1.1 & 0 & 0 & 0 & 0 & 4 & 14,81 & 16 & 59,26 & 7 & 25,93 \\
\hline Y1.2 & 0 & 0 & 0 & 0 & 2 & 7,41 & 21 & 77,78 & 4 & 14,81 \\
\hline Y1.1 & 0 & 0 & 0 & 0 & 4 & 14,81 & 12 & 44,44 & 11 & 40,74 \\
\hline Y1.2 & 0 & 0 & 0 & 0 & 5 & 18,52 & 14 & 51,85 & 8 & 29,63 \\
\hline $\mathrm{Y} 1.3$ & 0 & 0 & 0 & 0 & 2 & 7,41 & 16 & 59,26 & 9 & 33,33 \\
\hline Y1.4 & 0 & 0 & 0 & 0 & 6 & 22,22 & 15 & 55,26 & 6 & 22,22 \\
\hline
\end{tabular}

Untuk item pertanyaan pada indikator kepuasan terhadap audit mayoritas jawaban responden secara berurut khusus pada item pertanyaan (Y2.1.) yaitu 59,26\% atau 16 orang menyatakan setuju, 25,,93\% atau 7 orang menyatakan sangat setuju dan 14,81\% atau 4 orang menyatakan netral. Untuk item pertanyaan (Y1.2) yaitu 77,78\% atau 21 orang menyatakan setuju, $14,81 \%$ atau 8 orang menyatakan sangat setuju dan 7,41\% atau 2 orang menyatakan netral.

Untuk item pertanyaan pada indikator kepuasan kerja dengan rekan seprofesi mayoritas jawaban responden secara berurut khusus pada item pertanyaan (Y2.1) yaitu $44,44 \%$ atau 12 orang menyatakan setuju, $40.74 \%$ atau 11 orang menyatakan sangat setuju dan $14,81 \%$ atau 4 orang menyatakan netral. Untuk item pertanyaan (Y2.2) yaitu 51,85\% atau 14 orang menyatakan setuju, $29,63 \%$ atau 8 orang menyatakan sangat setuju dan 
Jurnal Akuntansi dan Keuangan (JAK)

Volume 6, No. 1 Februari Tahun 2021

Page: $111-123$

http://ojs.uho.ac.id/index.php/jak-uho/issue/archive

e-ISSN: 2088-4656

$18,52 \%$ atau 4 orang menyatakan netral. Untuk item pertanyaan (Y2.3) yaitu 59,26\% atau 16 orang menyatakan setuju, 33,33\% atau 9 orang menyatakan sangat setuju, 7,41\% atau 2 orang menyatakan netral. Untuk item pertanyaan (Y2.4) yaitu 55,26\% atau 15 orang menyatakan setuju, 22,22\% atau 6 orang menyatakan sangat setuju, 22,22\% atau 6 orang menyatakan netral.

Uji Validitas Dan Reliabilitas

Tabel 4. 6

Tabel Uji validitas $X$

\begin{tabular}{|c|c|c|c|c|}
\hline Variabel & Item Pernyataan & $\begin{array}{l}\text { Person } \\
\text { Correlat ion }\end{array}$ & $\begin{array}{l}\text { rtabel } \\
\text { (Taraf } \\
\text { Siginifi } \\
\text { kansi } \\
5 \% \text { ) }\end{array}$ & Ket \\
\hline \multirow{11}{*}{$x$} & $\mathrm{X} 1.1$ & 0,489 & \multirow{10}{*}{0,30} & Valid \\
\hline & $\mathrm{X} 1.2$ & 0,363 & & Valid \\
\hline & $\mathrm{X} 1.3$ & 0,324 & & Tidak Valid \\
\hline & $\mathrm{X} 1.4$ & 0,421 & & Valid \\
\hline & $\mathrm{X} 1.5$ & 0,240 & & Tidak Valid \\
\hline & $\mathrm{X} 1.6$ & 0,249 & & Tidak Valid \\
\hline & $\mathrm{X} 1.7$ & 0,508 & & Valid \\
\hline & $\mathrm{X} 2.1$ & 0,553 & & Valid \\
\hline & $\mathrm{X} 2.2$ & 0,263 & & Tidak Valid \\
\hline & $\mathrm{X} 2.3$ & 0,536 & & Valid \\
\hline & $\mathrm{X} 2.4$ & 0,500 & & Valid \\
\hline
\end{tabular}

Sumber : Data Prima diolah tahun 2020

Variable komitmen professional terdiri dari 11 butir pertanyaan, berdasarkan table uji validitas $X$ menunjukkan terdapat 4 butir pertanyaan yang tidak valid karena nilai korelasi dibawah 0,30 yaitu butir X13 dengan $r$ hitung $0,324<0,30$, butir X1.5 dengan $r$ hitung $0,240<0,30$, butir X1.6 dengan $r$ hitung $0,249<0,30$, butir X2.2 dengan $r$ hitung $0,263<0,30$. Dengan demikian keempat butir pertanyaan tersebut dikeluarkan dari instrument penelitian, sehingga variable komitmen professional terdiri dari 7 butir pertanyaan valid.

Tabel 4.7

Tabel Uji Validitas Y

\begin{tabular}{|l|l|l|l|l|}
\hline \multirow{5}{*}{ Variabel } & Item Pernyataan & $\begin{array}{l}\text { Person } \\
\text { Correlat ion }\end{array}$ & $\begin{array}{l}\text { rtabel } \\
\text { (Taraf } \\
\text { Siginifi kansi } \\
\text { 5\%) }\end{array}$ & Ket \\
\hline \multirow{5}{*}{$Y$} & Y1.1 & 0,685 & & Valid \\
\cline { 2 - 3 } & Y1.2 & 0,359 & & Valid \\
\cline { 2 - 3 } & Y2.1 & 0,740 & Valid \\
\cline { 2 - 3 } & Y2.2 & 0,652 & Valid \\
\cline { 2 - 3 } & Y2.3 & 0,635 & Valid \\
\cline { 2 - 3 } & Y2.4 & 0,678 & Valid \\
\hline
\end{tabular}

Sumber : Data Prima diolah tahun 2020 
Jurnal Akuntansi dan Keuangan (JAK)

Volume 6, No. 1 Februari Tahun 2021

Page: $111-123$

http://ojs.uho.ac.id/index.php/iak-uho/issue/archive

e-ISSN: 2088-4656

Variable kepuasan kerja terdiri dari 6 butir pertanyaan, berdasarkan tabel variable kepuasan kerja diatas nilai $r$ hitung seluruh butir pertanyaan lebih besar 0,30, dengan demikian seluruh butir pertanyaan dinyatakan valid.

Tabel 4.8

Ringkasan Hasil Uji Reliabilitas

\begin{tabular}{|l|l|l|l|}
\hline Variabel & $\begin{array}{l}\text { Reabilitas } \\
\text { Coeficient }\end{array}$ & $\begin{array}{l}\text { Cronbach's } \\
\text { Alpha }\end{array}$ & Keterangan \\
\hline Komitmen Profesional (X) & $\begin{array}{l}\text { 11 Item } \\
\text { Pernyataan }\end{array}$ & 0,749 & Reliabel \\
\hline Kepuasan Kerja Auditor (Y) & $\begin{array}{l}\text { 6 Item } \\
\text { Pernyataan }\end{array}$ & 0,832 & Reliabel \\
\hline
\end{tabular}

Sumber : Hasil Pengolahan Data Primer 2020

Dapat dilihat dari tabel 4.10 di atas menunjukkan bahwa alpha variabel komitmen professional $(\alpha \mathrm{X})$ sebesar 0,749 dan alpha variabel kepuasan kerja Auditor $(\alpha \mathrm{Y})$ sebesar 0,832 lebih besar dari 0,60 maka hasil uji reabilitas dapat dinyatakan reliabel.

Uji Analisis Faktor

Tabel 4. 9

Hasil Uji Analisis Faktor

\begin{tabular}{|l|l|l|l|l|l|}
\hline \multicolumn{9}{|l}{ Anti-image Matrices } & X1.T & X2.T & Y1.T & Y2.T \\
\hline \multirow{4}{*}{ Anti-image Covariance } & X1.T & .529 & -.135 & .042 & -.141 \\
\cline { 2 - 6 } & X2.T & -.135 & .429 & -.087 & -.105 \\
\cline { 2 - 6 } & Y1.T & .042 & -.087 & .389 & -.188 \\
\cline { 2 - 6 } & Y2.T & -.141 & -.105 & -.188 & .278 \\
\hline \multirow{5}{*}{ Anti-image Correlation } & X1.T & $.821^{\mathrm{a}}$ & -.283 & .092 & -.368 \\
\cline { 2 - 6 } & X2.T & -.283 & $.856^{\mathrm{a}}$ & -.213 & -.305 \\
\cline { 2 - 6 } & Y1.T & .092 & -.213 & $.765^{\mathrm{a}}$ & -.571 \\
\cline { 2 - 6 } & Y2.T & -.368 & -.305 & -.571 & $.734^{\mathrm{a}}$ \\
\hline
\end{tabular}

a. Measures of Sampling Adequacy(MSA)

Sumber : Data Primer Diolah Tahun 2020

- Anti image matrices berguna untuk mengetahui dan menentukan variable mana saja yang layak pakai dalam analisis factor.

- Perhatikan bagian anti-image correlation, pada table tersebut terdapat kode huruf (a) yang artinya tanda untuk measure of sampling adequacy (MSA).

- Diketahui nilai MSA dari masing-masing yang diteliti adalah sebagai berikut: indikator X1 sebesar 0,821, indikator X.2 sebesar 0,856, indikator Y1 sebesar 0,765, indikator Y.2 0,734.

- Persayaratan yang harus terpenuhi dalam analisis factor adalah nilai MSA > 0,50. Dari hasil di atas diketahui bahwa nilai MSA untuk semua variable yang diteliti adalah $>0,50$, maka semua variable layak untuk dilakukan analisis faktor.

- Catatan: jika ada variable yang memiliki MSA <0,50 maka solusinya adalah dengan melakukan proses analisis ulang hanya untuk variable yang memiliki nilai MSA > 0,50 .

\section{Uji Asumsi Klasik}

a. Uji Normalitas

Uji normalitas dilakukan untuk mengetahui apakah dalam model regresi, variabel dependen dan variabel independen berdistribusi normal atau tidak. Model regresi yang 
Jurnal Akuntansi dan Keuangan (JAK)

Volume 6, No. 1 Februari Tahun 2021

Page: $111-123$

http://ojs.uho.ac.id/index.php/iak-uho/issue/archive

e-ISSN: 2088-4656

baik adalah yang berdistribusi normal atau mendekati normal. Untuk menguji normalitas ini dapat diketahui dari tampilan grafik normal probability plot ( $P-P$ Plot Test) dan grafik histogram. Jika data menyebar disekitar garis diagonal dan mengikuti arah garis diagonal, maka model regresi memenuhi asumsi normalitas. Jika data menyebar jauh dari garis diagonal atau tidak mengikuti arah garis diagonal maka model regresi tidak memenuhi asumsi normalitas.

Gambar 4. 1

Normal Probability Plot

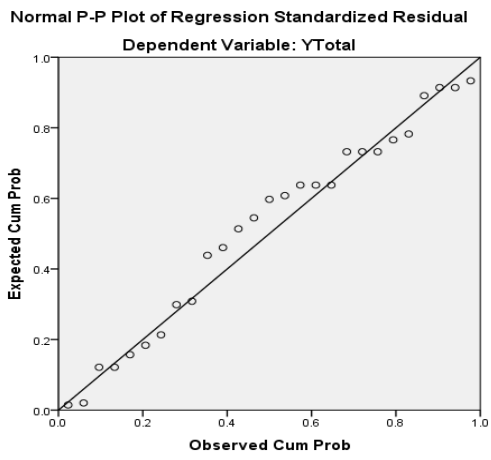

Sumber : Data Primer diolah tahun 2020

Gambar 4.1 normal probability plot di atas, terlihat bahwa titik-titik menyebar disekitar garis diagonal, serta penyebarannya mengikuti arah garis diagonal.

\section{Gambar 4. 2}

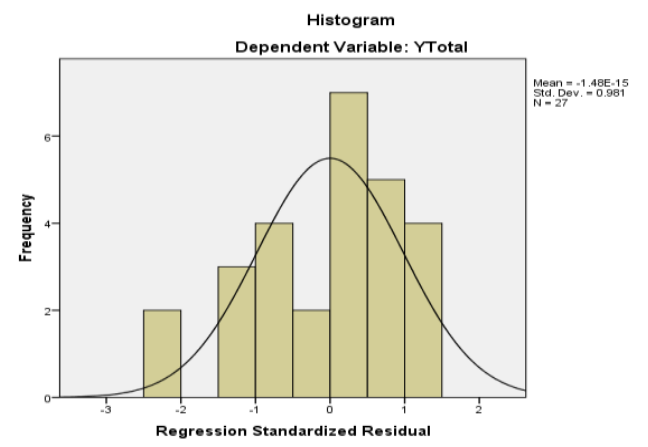

\section{Histogram}

Sumber : Data Primer diolah tahun 2020

Gambar 4.2 menunjukkan bahwa residual terdistribusi secara normal ditunjukan dengan pola yang berbentuk simetris, tidak melenceng ke kanan atau ke kiri. Hasil pengujian diatas menunjukkan bahwa model regresi telah memenuhi asumsi normalitas.

b. Uji Linearitas

Uji linearitas bertujuan untuk mengetahui apakah dua variabel secara signifikansi mempunyai pengaruh linear atau tidak. Pengambilan keputusan pengujian berdasarkan, jika nilai signifikansi > 0,05 maka terdapat hubungan yang linear dan jika nilai signifikansi < 0,05 tidak terdapat hubungan yang linear. 
Tabel 4. 10

Anova Table

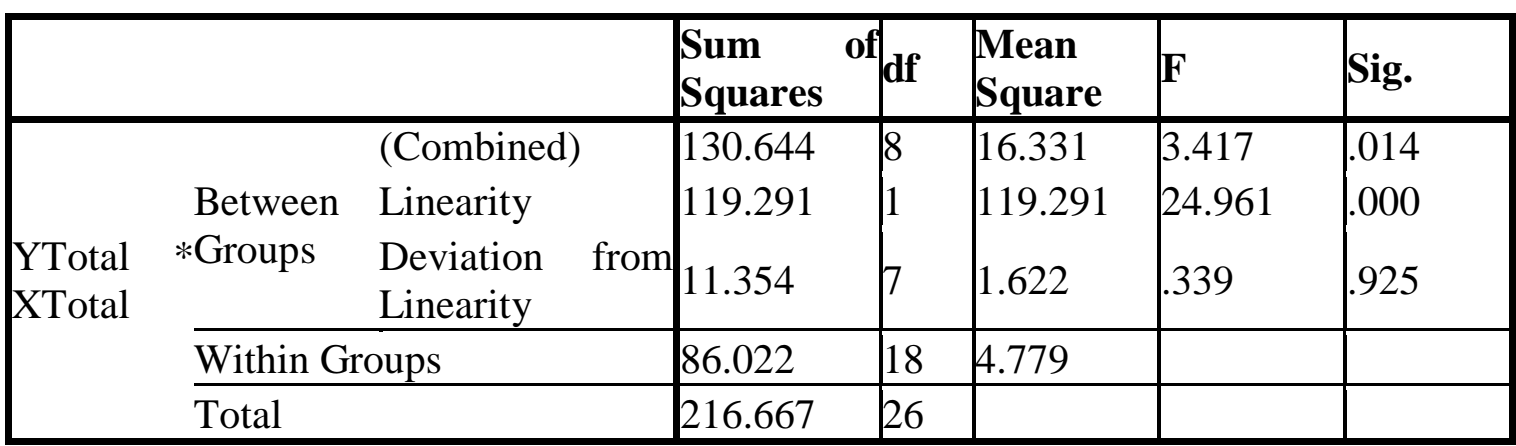

Dari hasil table pengujian 4.12 diatas, diketahui bahwa nilai signifikansi $0,925>$ 0,05 . Maka dapat disimpulkan bahwa terdapat hubungan linear yang signifikan antara komitmen professional dengan kepuasan kerja auditor.

c. Uji Heterokedastisitas

Tujuan dilakukannya uji heterokedastisitas adalah untuk menguji apakah model regresi terjadi ketidaksamaan varians dari residual dari satu pengamatan ke pengamatan lain. Jika varians dari residual dari satu pengamatan ke pengamatan yang lain tetap, maka disebut homokedastisitas. Model regresi yang baik ialah tidak terjadi heterokedastisitas

Gambar 4. 3

Hasil Uji Heterokedastisitas

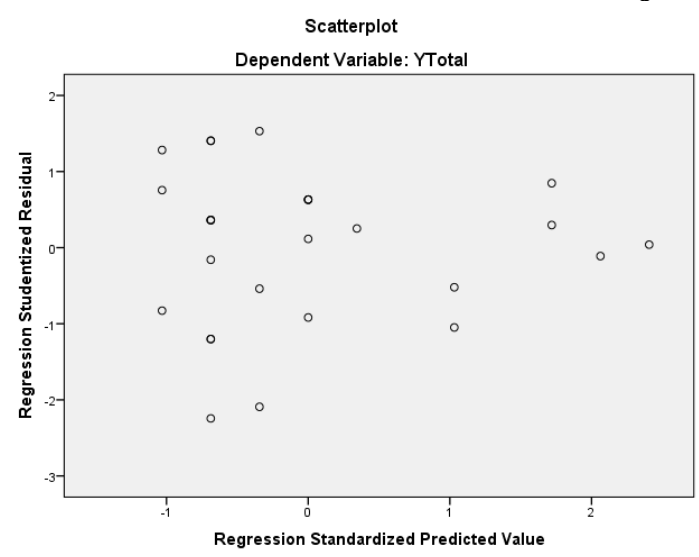

Sumber : Data Primer diolah tahun 2020

Dari Gambar 4.3 tersebut dapat dilihat bahwa titik titik data tidak terdapat pola yang jelas dan menyebar di atas dan di bawah angka 0 (nol) pada sumbu Y, sehingga dapat disimpulkan bahwa tidak ada heterokedastisitas dalam penelitian ini.

Uji Analisi Regresi Sederhana

Tabel 4. 11

Hasil Uji Analisis Regresi Linear Sederhana

\begin{tabular}{|c|c|c|c|c|c|c|}
\hline \multicolumn{7}{|c|}{ Coefficients $^{\mathrm{a}}$} \\
\hline \multirow{2}{*}{\multicolumn{2}{|c|}{ Model }} & $\begin{array}{l}\text { Unstan } \\
\text { Coeffi }\end{array}$ & & $\begin{array}{l}\text { Standardized } \\
\text { Coefficients }\end{array}$ & \multirow[t]{2}{*}{$\mathrm{T}$} & \multirow{2}{*}{ Sig. } \\
\hline & & $\mathrm{B}$ & Std. Error & Beta & & \\
\hline \multirow{2}{*}{1} & (Constant) & 9.831 & 6.265 & & 1.569 & .129 \\
\hline & XTotal & .736 & .133 & .742 & 5.534 & .000 \\
\hline
\end{tabular}

Sumber: Data angket yang telah diolah tahun 2020 
Dari Tabel 4.13 diatas menunjukkan hasil yang diperoleh nilai constant (a) sebesar 9,831, sedangkan nilai komitmen profesional (b/koefisien regresi) sebesar 0,736. Dari hasi tersebut dapat dimasukkan dalam persamaan regresinya sebagi berikut:

$\mathrm{Y}=\mathrm{a}+\mathrm{bX}+e$

$\mathrm{Y}=9,831+0,736 \mathrm{X}$

Hasil persamaan diatas dapat diterjemahkan konstanta sebesar 9,831 yang mengandung arti bahwa nilai konsistensi variabel komitmen profesional sebesar 9,831 koefisien regresi $\mathrm{X}$ sebesar $0,736 \mathrm{X}$ yang menyatakan bahwa penambahan $1 \%$ nilai komitmen profesional maka kepuasan kerja auditor akan bertambah sebesar 0,736. Koefisien regresi tersebut bernilai positif, sehingga dapat dikatakan bahwa arah pengaruh komitmen profesional (variabel X) kepuasan kerja auditor (variabel Y) adalah positif. Dan berdasarkan nilai signifikansi yang diperoleh dari tabel diatas sebesar $0,000<0,05$ sehingga dapat disimpulkan bahwa variabel komitmen profesional $(\mathrm{X})$ berpengaruh terhadap variabel hipotesis adalah:

a. Jika $t$ hitung $>\mathrm{t}$ tabel maka Ho ditolak dan Ha diterima

b. Jika $t$ hitung $<\mathrm{t}$ tabel maka Ho diterima dan Ha ditolak

Nilai t tabel dengan alpha 5\% dan jumlah sampel kepuasan kerja auditor (Y).

\section{Hasil Pengujian Hipotesis}

d. Uji Parsial (Uji-t)

Uji t dilakukan untuk menunjukkan seberapa jauh pengaruh antara variabel bebas dengan variabel terikat. Apabila nilai signifikan (Sig.) lebih kecil dari 0,05 maka suatu variabel dikatakan berpengaruh secara signifikan terhadap variabel yang lain. Adapun kriteria penerimaan dan penolakan. $\mathrm{n}$ dikurangi $\mathrm{k}$ jumlah variabel yang digunakan maka diperoleh $\mathrm{t}$ tabel sebesar 0.68443 .

Tabel 4. 12

Hasil Uji-t

\begin{tabular}{|c|c|c|c|c|c|c|}
\hline \multirow{2}{*}{\multicolumn{2}{|c|}{ Model }} & \multicolumn{2}{|c|}{$\begin{array}{l}\text { Unstandardized } \\
\text { Coefficients }\end{array}$} & \multirow{2}{*}{\begin{tabular}{|l} 
Standardized \\
Coefficients \\
Beta \\
\end{tabular}} & \multirow[t]{2}{*}{$\mathrm{T}$} & \multirow[t]{2}{*}{ Sig. } \\
\hline & & B & Std. Error & & & \\
\hline \multirow{2}{*}{1} & (Constant) & 9.831 & 6.265 & & 1.569 & .129 \\
\hline & XTotal & .736 & .133 & .742 & 5.534 & .000 \\
\hline
\end{tabular}

Sumber : Hasil Pengolahan Data Primer, 2020

Pada Tabel 4.14 diketahui bahwa nilai $t_{\text {hitung }}$ sebesar 5.534 lebih besar dari nilai $t_{\text {tabel }}$ 0.68443 dengan nilai sigifikansi $0,00<0,05$. Dapat diambil kesimpulan bahwa komitmen professional berpengaruh positif dan signifikan terhadap kepuasan kerja auditor karena nilai $t_{\text {hitung }}>t_{\text {tabel }}$ dan nilai Signifikan lebih kecil dari 0,05.

e. Koefisien Determinasi

Tujuan dari uji ini adalah untuk mengetahui seberapa besar pengaruh komitmen professional (X) terhadap kepuasan kerja auditor (Y). Nilai $\mathrm{R}^{2}$ menunjukkan seberapa besar proporsi dari total variasi variabel tidak bebas yang dapat dijelaskan oleh variabel penjelasnya. Semakin tinggi nilai $\mathrm{R}^{2}$ maka semakin besar proporsi dari total variasi variabel dependen yang dapat dijelaskan oleh variabel independen.

Untuk mengetahui seberapa besar pengaruh komitmen profesional(X) terhadap kepuasan kerja auditor (Y), dilakukan perhitungan statistik dengan menggunakan Koefisien Determinasi (KD). 
Tabel 4. 13

Hasil Uji Koefisien Determinasi

\begin{tabular}{|l|l|l|l|l|}
\hline Model & $\mathrm{R}$ & R Square & $\begin{array}{l}\text { Adjusted R } \\
\text { Square }\end{array}$ & $\begin{array}{l}\text { Std. Error of the } \\
\text { Estimate }\end{array}$ \\
\hline 1 & $.742^{\mathrm{a}}$ & .551 & .533 & .1974 \\
\hline
\end{tabular}

Sumber : Hasil Pengolahan Data Primer, 2020

Dari hasil Tabel 4.15 menjelaskan bahwa besarnya nilai hubungan (R) yaitu sebesar 0,742. Dari output tersebut diperoleh koefisien determinasi (R Square) sebesar 0,551 yang mengandung pengertian bahwa pengaruh variabel bebas komitmen profesional terhadap variabel terikat kepuasan kerja auditor adalah sebesar 55,1\%. Hal ini berarti bahwa ada variabel lain atau variabel epselon $(\varepsilon)$ sebesar $44,9 \%$ yang mempengaruhi variabel Y namun tidak diukur dalam penelitian.

\section{Pembahasan}

Berdasarkan hasil pengujian, diketahui bahwa komitmen profesional berpengaruh positif terhadap kepuasan kerja auditor, artinya auditor yang memiliki komitmen dalam bekerja maka akan memberikan kepuasan kerja bagi dirinya. Hal ini yang diperkuat dan didukung oleh nilai sig. lebih kecil dari nilai alpha artinya komitmen profesional berpengaruh terhadap kepuasan kerja auditor. Selanjutnya dapat dilihat hasil dari t hitung lebih besar dari t tabel artinya $\mathrm{H}_{0}$ ditolak dan $\mathrm{H}_{\mathrm{a}}$ diterima. Sehingga hal ini menunjukkan bahwa komitmen profesional memiliki pengaruh signifikan terhadap kepuasan kerja auditor di BPK Perwakilan Sulawesi Tenggara.

Hasil penelitian menunjukkan bahwa auditor pada Badan Pemeriksa Keuangan Perwakilan Provinsi Sulawesi Tenggara memiliki komitmen profesional baik. Auditor yang memiliki komitmen professional cenderung bekerja lebih baik sehingga merasakan kepuasan dalam bekerja.

Hasil penelitian ini sesuai dengan penelitian Zulfikar (2013) yang menyatakan bahwa secara parsial komitmen professional berpengaruh secara signifikan terhadap kepuasan kerja auditor. Namun berbeda dengan penelitian A.A. Gde Dwi Aditya dan Made Gede Wirakusuma (2013) menjelaskan bahwa komtimen prosesional tidak memiliki pengaruh signifikan terhadap kepuasan kerja auditor.

\section{Kesimpulan}

\section{KESIMPULAN DAN SARAN}

Berdasarkan hasil penelitian tentang pengaruh komitmen profesional terhadap kepuasan kerja auditor studi pada Badan Pemeriksa Keuangan Perwakilan Sulawesi Tenggara dan berbagai uraian yang telah dijelaskan dalam bab-bab sebelumnya, maka dapat disimpulkan bahwa: "Komitmen profesional memberikan Pengaruh signifikan terhadap tingkat kepuasan kerja. Secara hasil uji t atau parsial, komitmen profesional berpengaruh signifikan terhadap tingkat kepuasan kerja. Nilai $t_{\text {hitung }}$ lebih besar $t_{\text {tabel, }}$ yang berarti hipotesis Ha diterima bahwa komitmen professional berpengaruh signifikan terhadap kepuasan kerja auditor:.

\section{Saran}

1. Penelitian serupa dilakukan dengan memperluas cakupan penelitian yaitu mengirimkan kuesioner ke beberapa kantor perwakilan provinsi lain agar diperoleh kesimpulan yang lebih baik.

2. Mengevaluasi pertanyaan-pertanyaan dalam kuesioner agar pertanyaan tersebut dapat mewakili secara tepat variabel yang hendak diukur. Peneliti juga menyarankan untuk menambah variabel yang lain yang mungkin dapat mempengaruhi kepuasan kerja 
Jurnal Akuntansi dan Keuangan (JAK)

Volume 6, No. 1 Februari Tahun 2021

Page: $111-123$

http://ojs.uho.ac.id/index.php/iak-uho/issue/archive

e-ISSN: 2088-4656

auditor, seperti budaya organisasi, komitmen organisasi, motivasi kerja sehingga dapat memberikan hasil yang berbeda.

3. Karena hasil olah data ini menggunakan keseluruhan, maka alangkah baiknya dilakukan pemisahan antara auditor senior dan junior untuk melihat mana yang lebih berkomitmen diantara mereka.

\section{DAFTAR PUSTAKA}

Aditya, AA. Gde Dwi, dan Made Gede Wirakusuma (2014). Pengaruh komitmen profesional terhadap kepuasan kerja auditor dengan motivasi sebagai variabel moderasi.

Agoes, Sukrisno. (2012). Auditing (Petunjuk Praktis Pemeriksaan Akuntan Oleh Akuntan Publik) Jilid I Edisi Keempat. Jakarta : Fakultas Ekonomi.

Aswar, Wiwin. (2014). Pengaruh Aturan Etika dan Komitmen Profesi Terhadap Profesionalisme Auditor Internal Pada Inspektorat Kota Kendari. Sulawesi Tenggara.

Badan Pemeriksa Keuangan Republik Indonesia. https://sultra.bpk.go.id/sejarah/. Diakses tanggal 20 november 2020.

Badan Pemeriksa Keuangan Republik Indonesia. https://sultra.bpk.go.id/strukturorganisasi/. Diakses tanggal 20 november 2020

Bajuri, Achmad. (2013). Pengaruh Komitmen Terhadap Kepuasan Kerja Auditor Dengan Motivasi Sebagai Variabel Intervening.

Bhrasatya. (2010). Pengaruh komitmen organisasional dan komitmen profesional terhadap kepuasan kerja auditor.

Dwiyanto, agus. (2011). Mengembalikan kepercayaan publik melalui reformasi birokrasi. Jakarta : PT. Gramedia Pustaka Utama Putra.

Eko Hartanto. 2017. Teknik analisis regresi linier sederhana untuk penelitian kuantitatif(Online),

(https://www.academia.edu/12888898/teknik_analisis_regresi_linier_sederhana_u ntuk_penelitian_kuantitatif), diakses 20 november 2020.

Ghozali, Imam. (2016). Aplikasi Analisis Multivariete dengan program IBM SPSS 23. Semarang : Universitas Diponegoro.

Misbahuddin dan Hasan, Iqbal. 2013. Analisis Data Penelitian Dengan Statistik. Jakarta: BumiAksara.

Mutia, Ferby. (2016). Pengaruh Komitmen Organisasional, Komitmen Profesional, Motivasi Kerja, Konflik Peran, Ketidakjelasan Peran dan Kelebihan Peran terhadap Kepuasan Kerja Auditor pada Kantor Akuntan Publik di Pekanbaru, Padang dan Batam.

Suliyato. (2011). Ekonometrika terapan: teori dan aplikasi dengan SPSS. Edisi 1. Yogyakarta: ANDI

Sugiyono. (2015). Metode Penelitian Kuantitatif, Kualitatif, dan R\&D. Cetakan ke 22. Bandung : Penerbit Alfabeta.

Zulfikar (2013). Pengaruh Komitmen Profesional Terhadap Kepuasan Kerja Auditor. 